\title{
Molecular design of curcumin analogues with potent antioxidant properties and thermodynamic evaluation of their mechanism of free radical scavenge
}

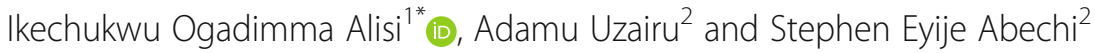

\begin{abstract}
Background: Free radical attack of cellular structures in the human system is the major cause of various forms of degenerative diseases. Consequently, recent research has been focused on the development of new antioxidants with more efficient free radical scavenging potentials. Ligand-based virtual screening was employed in the rational design of potent antioxidant derivatives of curcumin by the density functional theory method. Various antioxidant descriptors that characterize the three major mechanisms of free radical scavenge, namely, hydrogen atom transfer (HAT), single electron transfer followed by proton transfer (SET-PT), and sequential proton loss electron transfer (SPLET), were calculated. Also, the spin density distribution on the generated radicals and the frontier orbital distribution and energy of the studied compounds were evaluated in order to gain further insight on the reaction mechanism. The reaction Gibbs free energy for scavenging the two important peroxyl radicals ( $\mathrm{HOO}$. and $\mathrm{CH}_{3} \mathrm{OO}$.) was calculated in order to evaluate the preferred mechanism of free radical scavenge by these compounds.
\end{abstract}

Results: The investigated compounds were able to scavenge $\mathrm{HOO}$. and $\mathrm{CH}_{3} \mathrm{OO}$. radicals by HAT and SPLET mechanisms in the gas phase and aqueous solution, based on the computed results of reaction enthalpies and Gibbs free energy. The SET-PT mechanism for these compounds was observed to be thermodynamically unfeasible in the gas phase. However, the thermodynamic feasibility of free radical scavenge by SET-PT mechanism was observed in aqueous solution. Among the investigated compounds, MCC 009 (1E,4E)-1-(3-(aminomethyl)-4hydroxyphenyl)-5-(4-hydroxy-3-((hydroxy (methyl)amino)methyl)phenyl)penta-1,4-dien-3-one at the 19-OH position possessed the highest capacity to scavenge both $\mathrm{HOO}$. and $\mathrm{CH}_{3} \mathrm{OO}$. radicals by HAT, SET-PT, and SPLET mechanisms. The reaction Gibbs free energy of scavenging $\mathrm{HOO}$. radical by this molecule in the gas phase and aqueous solution is $\Delta_{r} G_{B D E g a s}=-58.18, \Delta_{r} G_{B D E H_{2} O}=-73.77, \Delta_{r} G_{\text {AlPgas }}=611.48, \Delta_{r} G_{A I P H_{2} O}=-74305.49, \Delta_{r} G_{P D E g a s}=$ $-669.66, \Delta_{r} G_{P D E H_{2} O}=74231.72, \Delta_{r} G_{\text {PAgas }}=-271.40, \Delta_{r} G_{P A H_{2} O}=-73.09, \Delta_{r} G_{\text {ETEgas }}=213.22$, and $\Delta_{r} G_{E T E H_{2} O}=-0.69$.

Conclusion: New set of curcumin derivatives with potent free radical scavenging properties was successfully designed, and their mechanism of free radical scavenging evaluated by thermodynamic studies. This research is a gateway to the exploitation of the considered curcumin derivatives in food chemistry and pharmacy.

Keywords: Antioxidant, Curcumin, Free radical, Molecular design, Reaction mechanism

\footnotetext{
*Correspondence: ikeogadialisi@gmail.com; ialisi@fudutsinma.edu.ng

'Department of Applied Chemistry, Federal University Dutsinma, PMB 5001

Dutsinma, Katsina State, Nigeria

Full list of author information is available at the end of the article
}

\section{Springer Open}

(๑) The Author(s). 2020 Open Access This article is licensed under a Creative Commons Attribution 4.0 International License, which permits use, sharing, adaptation, distribution and reproduction in any medium or format, as long as you give appropriate credit to the original author(s) and the source, provide a link to the Creative Commons licence, and indicate if changes were made. The images or other third party material in this article are included in the article's Creative Commons licence, unless indicated otherwise in a credit line to the material. If material is not included in the article's Creative Commons licence and your intended use is not permitted by statutory regulation or exceeds the permitted use, you will need to obtain permission directly from the copyright holder. To view a copy of this licence, visit http://creativecommons.org/licenses/by/4.0/. 


\section{Background}

The 1,5-diphenylpenta-1,4-dien-3-one derivatives are monoketone curcumin analogues with a broad range of biological activities. Various studies on these compounds show that they possess anti-parasitical (Aher et al. 2011; Din et al. 2014; Din et al. 2016), leishmanicidal (Chauhan et al. 2018; Singh and Chauhan 2018), aldose reductase inhibitory (Kondhare et al. 2019), and antioxidant (Naik et al. 2011) activities. The optical properties of these compounds have also been documented (Sunil et al. 2014).

Antioxidants are substances that have the ability to scavenge free radicals, thereby preventing the onset of oxidative stress (Alisi et al. 2019a). Antioxidants employ various mechanisms to exert their influence. Three major mechanisms of free radical scavenge by antioxidants have been recognized. These include hydrogen atom transfer (HAT), single electron transfer followed by proton transfer (SETPT), and sequential proton loss electron transfer (SPLET) (Galano et al. 2016; Vo et al. 2018).

Free radicals are molecules or their fragments that contain unpaired electrons in their atomic or molecular orbitals. Free radicals are highly reactive species and have the ability to initiate chain reactions that propagates their molecular damage on proteins and lipids (Alisi et al. 2018a). When the level of free radicals in the human system exceed a threshold level, oxidative stress results. Oxidative stress plays a vital role in the pathogenesis and pathophysiology of various chronic health disorders such as osteoporosis, cancer, diabetes, and neurodegenerative conditions (Pisoschi and Pop 2015; Tan et al. 2018; Yeung et al. 2019). These conditions with time develop resistance to most drugs used for their treatment. This trend has aroused a great need to develop highly efficient free radical scavengers. A method widely employed in the design of new chemical entities with potent biological activities is in silico design by virtual screening through the method of quantitative structure activity relationship (QSAR).

In silico design by virtual screening has been employed in the rational design of various compounds with potent antioxidant activities such as hydrazones (Alisi et al. 2019b), 1,3,4-oxadiazoles (Alisi et al. 2020), Schiff base1,2,4-triazoles bearing butylated hydroxytoluene moiety (Yehye et al. 2016), and phenolic derivatives bearing NO donor groups (Mitra et al. 2011a). Recently, it has also been employed in the design of electrolytic solvents (Marcou et al. 2019), membranolytic anticancer peptides (Gabernet et al. 2019), graphene oxide membranes with variable water content and flake oxygen content (Williams et al. 2019), and linear and cyclic pentapeptide ligands potentially active against the influenza A virus (Perrier et al. 2019).

QSAR is based on the principle that the biological activities of compounds are a function of their molecular structure (Fourches and Ash 2019). QSAR is a valuable approach that has been employed extensively to investigate the structure property relationships of various compounds and their associated biological activities (Alisi et al. 2018b; Gul et al. 2019; Yousefinejad et al. 2019).

Density-functional theory (DFT) is a computational quantum mechanical modeling method employed to investigate the structural, magnetic, and electronic properties of matter. The results of DFT computations have been employed to investigate the antioxidant properties and energetics of free radical scavenge of various compounds (Hernandez et al. 2020; Yusuff et al. 2019; Boulebd et al. 2020; Zhou et al. 2019).

In the present research, the earlier developed QSAR model for curcumin antioxidants was employed in the design of a new set of 1,5-diphenylpenta-1,4-dien-3-one derivatives. Their antioxidant activities were subsequently determined by the leverage approach using the same model. Furthermore, the mechanism of free radical scavenge by these compounds was investigated via thermodynamic studies by the (DFT) method.

\section{Methods}

\section{Design of new compounds}

The design of a new set of curcumin antioxidants was accomplished by ligand-based virtual screening using the earlier developed QSAR model for curcumin antioxidants (Alisi et al. 2018c). This was performed by insertion, deletion, and substitution of various substituents on the template molecule using the curcumin antioxidant model as a basis (Asadollahi et al. 2011; Mitra et al. 2011b). This model has an applicability domain with a leverage threshold value of 0.649. In the present research, compound M29 (Fig. 1) listed in Table 1 of (Alisi et al. 2018c) was chosen as a template based on its impressive antioxidant activity $\left(\mathrm{pIC}_{50}=6.260\right)$.

All molecular structures were drawn using Chem Draw Program (Li et al. 2004). While geometry optimization of the relevant chemical structures was accomplished using Spartan 14 program (Shao et al. 2006), this was executed at the DFT level using the Becke three-parameter Lee-Yang-Parr hybrid functional (B3LYP) in combination with 6-311G* basis set without symmetry constraints. The optimized structures were converted to Sdf files and submitted to the PADEL program package version 2.20 (Yap 2011). The above procedures resulted in the generation of quantum chemical and molecular descriptors for each molecular structure. The antioxidant activities of the modified structures were further calculated using the curcumin antioxidant model. Subsequently, their applicability domain was accessed by the leverage approach. 


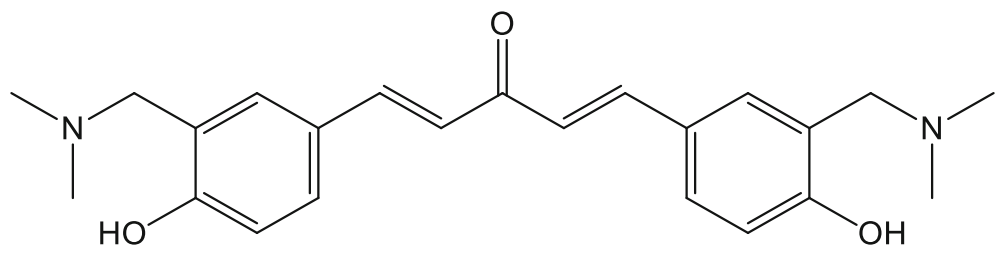

Fig. 1 Parent molecule (M29) used as template

\section{Computation of antioxidant descriptors}

Various antioxidant descriptors that characterize the various mechanisms of free radical scavenge were calculated in the gas phase and aqueous solution as presented below.

\section{The homolytic bond dissociation enthalpy (BDE)}

This descriptor was calculated under standard conditions of $1 \mathrm{~atm}$ and $298.15 \mathrm{~K}$ using Eq. (1). It represents the standard enthalpy change at a given temperature when a particular chemical bond is broken under standard conditions (Ruscic 2015). Its value determines the stability of the corresponding hydroxyl group. The lower $\mathrm{BDE}$ value for a given antioxidant indicates the low stability of the $\mathrm{O}-\mathrm{H}$ bond. This results in a higher tendency to break the corresponding $\mathrm{O}-\mathrm{H}$ bond (Sun and Jin 2013). This results in better antioxidant activity of the considered molecule.

$$
B D E=H_{\text {radical }}+H_{H}-H_{\text {neutral }}
$$

Adiabatic ionization potential (AIP) values represent the ability of the antioxidant to transfer electrons to the free radical. It describes the process of electron donation by the antioxidant. The lower the AIP value for a given molecule, the easier is the ability to transfer electrons. Molecules with lower AIP values have higher tendency to undergo ionization. Such molecules have been observed topossess stronger antioxidant activities (Özbakır Issın 2016). The AIP values were estimated using Eq. (2):

Table 1 Designed curcumin derivatives, their predicted antioxidant activities, and leverage values

\begin{tabular}{|c|c|c|c|}
\hline $\begin{array}{l}\text { Comp } \\
\text { No. }\end{array}$ & Compound structure/name & $p / C_{50}$ & Leverage \\
\hline MCC 001 & (1E, 4E)-1,5-bis(3-(aminomethyl)-4-hydroxyphenyl)penta-1,4-dien-3-one & 5.097 & 0.602 \\
\hline MCC 002 & (1E, 4E)-1,5-bis(4-hydroxy-3-((hydroxyamino)methyl)phenyl)penta-1,4-dien-3-one & 4.131 & 0.556 \\
\hline MCC 003 & $(1 \mathrm{E}, 4 \mathrm{E})-1,5-$ bis(4-hydroxy-3-((methylamino)methyl)phenyl)penta-1,4-dien-3-one & 2.694 & 0.610 \\
\hline MCC 004 & (1E, 4E)-1,5-bis(4-hydroxy-3-((hydroxyl (methyl)amino)methyl)phenyl)penta-1,4-dien-3-one & 5.626 & 0.568 \\
\hline MCC 005 & (1E,4E)-1-(3-(aminomethyl)-4-hydroxyphenyl)-5-(4-hydroxy-3-((hydroxyamino)methyl)phenyl)penta-1,4-dien-3-one & 4.697 & 0.225 \\
\hline MCC 006 & $\begin{array}{l}\text { (1E,4E)-1-(3-((dimethylamino)methyl)-4-hydroxyphenyl)-5-(4-hydroxy-3-((hydroxyamino)methyl)phenyl)penta-1,4-dien-3- } \\
\text { one }\end{array}$ & 5.521 & 0.271 \\
\hline MCC 007 & (1E,4E)-1-(3-(aminomethyl)-4-hydroxyphenyl)-5-(3-((dimethylamino)methyl)-4-hydroxyphenyl)penta-1,4-dien-3-one & 6.334 & 0.386 \\
\hline MCC 008 & (1E,4E)-1-(3-(aminomethyl)-4-hydroxyphenyl)-5-(4-hydroxy-3-((methylamino)methyl)phenyl)penta-1,4-dien-3-one & 4.054 & 0.310 \\
\hline MCC 009 & (1E,4E)-1-(3-(aminomethyl)-4-hydroxyphenyl)-5-(4-hydroxy-3-((hydroxy (methyl)amino)methyl)phenyl)penta-1,4-dien-3-one & 6.475 & 0.236 \\
\hline MCC 010 & (1E,4E)-1-(3-(aminomethyl)-4-hydroxyphenyl)-5-(3-((dihydroxyamino)methyl)-4-hydroxyphenyl)penta-1,4-dien-3-one & 4.162 & 0.252 \\
\hline MCC 011 & (1E,4E)-1-(3-(aminomethyl)-4-hydroxyphenyl)-5-(4-hydroxy-3-((methylamino)methyl)phenyl)penta-1,4-dien-3-one & 4.343 & 0.162 \\
\hline MCC 012 & (1E,4E)-1-(3-((dimethylamino)methyl)-4-hydroxyphenyl)-5-(4-hydroxy-3-((methylamino)methyl)phenyl)penta-1,4-dien-3-one & 4.809 & 0.296 \\
\hline MCC 013 & $\begin{array}{l}\text { (1E,4E)-1-(3-(dihydroxyamino)methyl)-4-hydroxyphenyl)-5-(3-((dimethylamino)methyl)-4-hydroxyphenyl)penta-1,4-dien-3- } \\
\text { one }\end{array}$ & 4.62 & 0.253 \\
\hline MCC 014 & $\begin{array}{l}\text { (1E,4E)-1-(3-((dihydroxyamino)methyl)-4-hydroxyphenyl)-5-(4-hydroxy-3-((hydroxy (methyl)amino)methyl)phenyl)penta-1, } \\
\text { 4-dien-3-one }\end{array}$ & 3.861 & 0.403 \\
\hline MCC 015 & $\begin{array}{l}\text { (1E,4E)-1-(3-((dimethylamino)methyl)-4-hydroxyphenyl)-5-(4-hydroxy-3-((hydroxy (methyl)amino)methyl)phenyl)penta-1,4- } \\
\text { dien-3-one }\end{array}$ & 6.282 & 0.344 \\
\hline MCC 016 & $\begin{array}{l}\text { (1E,4E)-1-(3-((dihydroxyamino)methyl)-4-hydroxyphenyl)-5-(4-hydroxy-3-((hydroxyamino)methyl)phenyl)penta-1,4-dien-3- } \\
\text { one }\end{array}$ & 3.144 & 0.397 \\
\hline MCC 017 & (1E, 4E)-1,5-bis(3-((dihydroxyamino)methyl)-4-hydroxyphenyl)penta-1,4-dien-3-one & 2.788 & 0.625 \\
\hline
\end{tabular}




$$
A I P=H_{\text {cation radical }}+H_{\text {electron }}-H_{\text {neutral }}
$$

The proton dissociation enthalpy (PDE) describes the ability of the cationic radical of the antioxidant to donate a proton to the free radical. The computation of PDE values was accomplished using Eq. (3). Antioxidants with lower PDE values are more susceptible to proton abstraction (Mikulski et al. 2014).

$$
P D E=H_{\text {radical }}+H_{H^{+}}-H_{\text {cation radical }}
$$

Proton affinity (PA) for a given molecule is the negative of its molar enthalpy change at $298.15 \mathrm{~K}$. lower PA values result in higher antioxidant activity of molecules. The PA value was estimated according to Eq. (4):

$$
P A=H_{\text {anion }}+H_{H^{+}}-H_{\text {neutral }}
$$

The electron transfer enthalpy (ETE) represents the ability of the antioxidant anion to transfer electrons to the free radical. The lower the ETE value for a given molecule, the more active is the resulting phenoxide anion. Equation (5) was employed in the computation of the ETE values.

$$
E T E=H_{\text {radical }}+H_{\text {electron }}-H_{\text {anion }}
$$

where $H_{\text {radical }}$ is the total enthalpy of phenoxyl radical, $H_{H}$ is the total enthalpy of the hydrogen atom, $H_{\text {neutral }}$ is the total enthalpy of neutral compound, $H_{H^{+}}$is the total enthalpy of the proton, $H_{\text {cation radical }}$ is the total enthalpy of the cation radical, $H_{\text {electron }}$ is the total enthalpy of the electron, and $H_{\text {anion }}$ is the total enthalpy of the anion.

In this study, the total enthalpy of the species was obtained as presented in Eq. (6). Also, energy was converted to enthalpy by adding RT (PV-work) term (Najafi et al. 2011).

$$
H=E_{0}+Z P E+H_{\text {trans }}+H_{\text {rot }}+H_{v i b}+R T
$$

where $E_{0}$ is the total energy at $0 \mathrm{~K}, \mathrm{ZPE}$ is the zeropoint vibrational energy, and $H_{\text {trans }}, H_{\text {rot }}$ and $H_{v i b}$ are the translational, rotational, and vibrational contributions to the enthalpy respectively.

The following values were employed in the computation of the antioxidant descriptors presented above: $H(H \quad)_{\text {vacuum }}=-1312.479673 \mathrm{~kJ} / \mathrm{mol}, H\left(H^{+}\right)_{\text {vacuum }}=6.19$ $61805 \mathrm{~kJ} / \mathrm{mol}, H\left(e^{-}\right)_{\text {vacuum }}=3.14534924 \mathrm{~kJ} / \mathrm{mol}, H(H)_{\text {wa- }}$ ter $=-3.9907603 \mathrm{~kJ} / \mathrm{mol}, \quad H\left(H^{+}\right)_{\text {water }}=-1090.00266 \mathrm{~kJ} /$ $\mathrm{mol}$, and $H\left(e^{-}\right)_{h y d r}=-105 \mathrm{~kJ} / \mathrm{mol}$ (Nenadis and Tsimidou 2012; Bartmess 1994; Bizarro et al. 1999; Rimarcik et al. 2010). Also, geometry optimization of all molecular structures in the gas phase was performed at the DFT/ B3LYP/6-311G* level of theory. Water $(\varepsilon=78.39)$ is the physiological medium of human living cells. Consequently, the computation of the solvation effect of water on the antioxidant activity was accomplished using the self-consistent reaction field (SCRF) method with a polarized continuum model (PCM) (Li et al. 2018; Bayat and Fattahi 2017) at the DFT/B3LYP/6-31G* level.

\section{Investigation of the thermodynamically favored mechanism}

The reaction Gibbs free energy $\left(\Delta_{r} G\right)$ was employed to determine the thermodynamically favored mechanism (Amic et al. 2017; Zheng et al. 2017). In this research, the change in Gibbs free energy between the reactants and products for the studied mechanisms of the reactions between the antioxidants and the peroxyl radicals (HOO. and $\mathrm{CH}_{3}-\mathrm{OO}$ ) was estimated in vacuum and water.

A thermodynamically favorable reaction is one whose Gibbs free energy change is exergonic (Eq. 7). In the present context, the exergonicity of the reaction between $\mathrm{HOO}$ and $\mathrm{CH}_{3}-\mathrm{OO}$. radicals and curcumin antioxidants was investigated.

$$
\Delta_{r} G=[G(\text { products })-G(\text { reactants })]<0
$$

The Gibbs free energy change for the HAT mechanism is given by $\Delta_{r} G_{B D E}$ (Eq. 8).

$$
\begin{aligned}
\Delta_{r} G_{B D E}= & {\left[G\left(H_{n-1} \text { Antiox }\right)+G(R H)\right] } \\
& -\left[G\left(H_{n} \text { Antiox }\right)+G\left(R^{*}\right)\right]
\end{aligned}
$$

The Gibbs free energy change for the SET-PT mechanism is given by $\Delta_{r} G_{A I P}$ (Eq. 9) and $\Delta_{r} G_{P D E}$ (Eq. 10), while that of the SPLET mechanism is given by $\Delta_{r} G_{P A}$ (Eq. 11) and $\Delta_{r} G_{E T E}$ (Eq. 12).

$$
\begin{aligned}
\Delta_{r} G_{\text {AIP }}= & {\left[G\left(H_{n-1} \text { Antiox }^{\cdot+}\right)+G\left(R^{-}\right)\right] } \\
& -\left[G\left(H_{n} \text { Antiox }\right)+G\left(R^{*}\right)\right]
\end{aligned}
$$

$$
\begin{aligned}
\Delta_{r} G_{P D E}= & {\left[G\left(H_{n-1} \text { Antiox }^{*}\right)+G(R H)\right] } \\
& -\left[G\left(H_{n-1} \text { Antiox }^{\circ+}\right)+G\left(R^{-}\right)\right] \\
\Delta_{r} G_{P A}= & {\left[G\left(H_{n-1} \text { Antiox }^{-}\right)+G(R H)\right] } \\
- & {\left[G\left(H_{n} \text { Antiox }\right)+G\left(R^{-}\right)\right] } \\
\Delta_{r} G_{E T E}= & {\left[G\left(H_{n-1} \text { Antiox }^{*}\right)+G\left(R^{-}\right)\right] } \\
& -\left[G\left(H_{n-1} \text { Antiox }^{-}\right)+G\left(R^{\bullet}\right)\right]
\end{aligned}
$$

where $G\left(H_{n} A n t i o x\right)$ is the Gibbs free energy of neutral antioxidant, $G\left(H_{n-1}\right.$ Antiox $\left.{ }^{\circ}\right)$ is the Gibbs free energy of phenoxyl radical, $G\left(R^{*}\right)$ is the Gibbs free energy of free radical, $G(H R)$ is the Gibbs free energy of product formed by hydrogen abstraction to free radical, $G\left(H_{n-}\right.$ 
${ }_{1}$ Antiox $\left.^{*+}\right)$ is the Gibbs free energy of cation radical, $G\left(H^{+}\right)$is the Gibbs free energy of proton, $G\left(R^{-}\right)$is the Gibbs free energy of free radical anion, and $G\left(H_{n-}\right.$ ${ }_{1}$ Antiox $\left.^{-}\right)$is the Gibbs free energy of anion.

The Gibbs free energy of the electron $\left(\mathrm{e}^{-}\right)$and proton $\left(\mathrm{H}^{+}\right)$employed in gas phase computations is $-3.72 \mathrm{~kJ} /$ $\mathrm{mol}$ and $-26.28 \mathrm{~kJ} / \mathrm{mol}$, respectively. However, in aqueous solution, $-156.8 \mathrm{~kJ} / \mathrm{mol}$ and $-1104.5 \mathrm{~kJ} / \mathrm{mol}$ were used as the Gibbs free energy for the electron and proton, respectively (Tissandier et al. 1998; Hwang and Chung 2005).

\section{Results}

\section{Discussion}

\section{Molecular design}

The $p I C_{50}$ standard residuals and leverage values of the newly designed curcumin antioxidants are presented in Table 1 . The applicability domain of curcumin antioxidants model has a leverage threshold, $h^{*}$ value of 0.6486 . From Table 1, we observe that all the designed molecules have leverage values less than the threshold leverage $\left(h<h^{*}\right)$. This is an indication that no structural outliers exist between the designed molecules. Also, the curcumin derivatives with best antioxidant activities include MCCM 07, MCCM 09, and MCCM 15 with $p I C_{50}$ values of 6.334, 6.275, and 6.282, respectively. Based on the above results, MCC 07, MCC 09, and MCC 15 were subjected to quantum chemical calculations in order to investigate their mechanism of free radical scavenge. The molecular structure and carbon atom numbering of these molecules are presented in Fig. 2.

\section{Analysis of the HAT mechanism}

The results of $\mathrm{BDE}(\mathrm{kJ} / \mathrm{mol})$ at various $\mathrm{OH}$ positions for MCC 007, MCC 009, and MCC 015 in the gas phase and aqueous solution are presented in Table 2. The two sites that are susceptible to HAT in MCC 007 molecule are the 4-OH and $16-\mathrm{OH}$ positions with $\mathrm{BDE}$ values of $(338.62 \mathrm{~kJ} / \mathrm{mol}$ and $309.24 \mathrm{~kJ} / \mathrm{mol})$, and $(1664.99 \mathrm{~kJ} / \mathrm{mol}$ and $1640.23 \mathrm{~kJ} / \mathrm{mol}$ ) in vacuum and water, respectively. For MCC 009, these are the 4-OH, $16-\mathrm{OH}$, and $19-\mathrm{OH}$ positions with BDE values of $337.20 \mathrm{~kJ} / \mathrm{mol}, 363.77 \mathrm{~kJ} /$ $\mathrm{mol}$, and $262.77 \mathrm{~kJ} / \mathrm{mol}$, respectively, in vacuum. In aqueous solution, these correspond to $1666.04 \mathrm{~kJ} / \mathrm{mol}$, $1694.05 \mathrm{~kJ} / \mathrm{mol}$, and $1591.29 \mathrm{~kJ} / \mathrm{mol}$, respectively. MCC 015 also has three possible sites which include the 3$\mathrm{OH}, 4-\mathrm{OH}$, and $16-\mathrm{OH}$ positions with $\mathrm{BDE}$ values of $263.87 \mathrm{~kJ} / \mathrm{mol}, 332.95 \mathrm{~kJ} / \mathrm{mol}$, and $308.85 \mathrm{~kJ} / \mathrm{mol}$, respectively, in the gas phase. In aqueous solution, the values are $1593.99 \mathrm{~kJ} / \mathrm{mol}, 1664.57 \mathrm{~kJ} / \mathrm{mol}$, and $1639.47 \mathrm{~kJ} / \mathrm{mol}$, respectively. From these results, we observe that MCC 007 4- $\mathrm{OH}, \mathrm{MCC} 009$ 16-OH, and MCC 015 4-OH are the sites with the highest tendency to form intramolecular hydrogen bonds with neighboring nitrogen atoms in both phases. This resulted in these positions having the highest BDE values for their respective molecules. Hydrogen atom transfer from these positions is the most difficult in comparison to other $-\mathrm{OH}$ positions. Subsequently, the primary target of free radical attack in MCC 007 is the $16-\mathrm{OH}$ position which has the lowest BDE value. Similarly, for MCC 009, the primary site for free radical attack is the $19-\mathrm{OH}$ position, while that of MCC 015 is the $3-\mathrm{OH}$ position (Table 2). When the BDE results for these compounds at their respective preferred sites of free radical scavenge are compared with that of phenol $(327.550 \mathrm{~kJ} / \mathrm{mol})$ which is usually chosen as a reference compound at the same level of theory, MCC 007 16-OH, MCC 009 19-OH, and MCC 015 3-OH have lower BDE values. This is an indication that these compounds possess higher tendency to undergo free radical scavenge through the HAT mechanism than phenol at<smiles>CC(=O)OC(=O)/C=C/c1ccc(O)c(CNN)c1</smiles><smiles>CC(=O)OCc1ccc(O)c(C=CC(=O)C=Cc2ccc(O)c(CN(C)O)c2)c1</smiles><smiles>CC(=O)OCc1cc(/C=C/C(=O)/C=C/c2ccc(O)c(CN(C)C)c2)ccc1O</smiles>

Fig. 2 Molecular structure and carbon atom numbering of MCC 007, MCC 009, and MCC 015 
Table 2 Antioxidant properties of designed curcumin derivatives calculated at the B3LYP/6-311G*/6-31G* level in vacuum and water. wce

\begin{tabular}{|c|c|c|c|c|c|c|c|c|c|c|c|}
\hline \multirow[t]{3}{*}{ Comp No } & \multirow{2}{*}{\multicolumn{2}{|c|}{$\frac{\mathrm{HAT}}{\mathrm{BDE}(\mathrm{kJ} / \mathrm{mol})}$}} & \multicolumn{4}{|l|}{ SET-PT } & \multicolumn{4}{|l|}{ SPLET } & \multirow{3}{*}{$\begin{array}{l}\text { Radical } \\
\text { spin } \\
\text { density }\end{array}$} \\
\hline & & & \multicolumn{2}{|c|}{ AIP $(\mathrm{kJ} / \mathrm{mol})$} & \multicolumn{2}{|c|}{ PDE (kJ/mol) } & \multicolumn{2}{|c|}{$\mathrm{PA}(\mathrm{kJ} / \mathrm{mol})$} & \multicolumn{2}{|c|}{ ETE $(\mathrm{kJ} / \mathrm{mol})$} & \\
\hline & Gas & Water & Gas & Water & Gas & Water & Gas & Water & Gas & Water & \\
\hline MCC 007 4-OH & 338.62 & 1664.99 & 314.61 & -1138.45 & 1316.45 & 1639.94 & 1380.12 & 340.13 & 280.32 & 138.17 & $2.32 \times 10^{-4}$ \\
\hline MCC 007 16-OH & 309.24 & 1640.23 & 385.21 & -1190.72 & 1275.23 & 1612.42 & 1367.07 & 335.80 & 263.99 & 109.08 & $2.23 \times 10^{-4}$ \\
\hline MCC 009 4-OH & 337.20 & 1666.04 & 381.14 & -1133.78 & 1277.88 & 1608.80 & 1381.49 & 369.88 & 277.54 & 135.78 & $2.35 \times 10^{-4}$ \\
\hline MCC 009 16-OH & 363.77 & 1694.05 & 392.64 & -1147.93 & 1292.95 & 1650.97 & 1386.82 & 370.41 & 298.78 & 132.63 & $2.41 \times 10^{-4}$ \\
\hline MCC 009 19-OH & 262.77 & 1591.29 & 480.51 & -1075.44 & 1104.08 & 1475.71 & 1362.35 & 339.24 & 222.24 & 30.40 & $2.30 \times 10^{-4}$ \\
\hline MCC 015 3-OH & 263.87 & 1593.99 & 485.66 & -1071.81 & 1100.03 & 1474.80 & 1358.25 & 323.44 & 227.10 & 79.55 & $2.14 \times 10^{-4}$ \\
\hline MCC 015 4-OH & 332.95 & 1664.57 & 397.26 & -1068.74 & 1257.51 & 1542.30 & 1363.37 & 335.93 & 296.52 & 140.83 & $2.42 \times 10^{-4}$ \\
\hline MCC 015 16-OH & 308.85 & 1639.47 & 315.61 & -1207.24 & 1315.06 & 1655.69 & 1358.59 & 332.73 & 267.30 & 112.52 & $2.25 \times 10^{-4}$ \\
\hline Phenol & 327.55 & 1632.72 & 572.78 & -1132.24 & 1076.59 & 1497.69 & 1462.89 & 141.47 & 186.48 & 300.24 & \\
\hline
\end{tabular}

these positions. Among the three considered molecules, MCC 009 at the 19-OH position has the best potential to undergo hydrogen atom transfer in the gas phase and aqueous solution. Also, the BDE values in the gas phase are by far lower than the results in aqueous solution. Thus, these molecules undergo HAT in the gas phase more readily than in aqueous solution.

\section{Analysis of the spin density distribution}

The spin density distribution is of great use in rationalizing the stability of the antioxidant radical (Zheng et al. 2017; Xue et al. 2014; Wang et al. 2015). The BDE in conjunction with the stability of the radicals is an important factor that influences the antioxidant activity of phenolics. Lower spin density distribution values result in higher delocalization of the spin density in a given radical. Such radicals possess higher stability, which is associated with lower BDE for a given antioxidant. The radical spin density results (IsoVal 0.002) for MCC 007, MCC 009, and MCC 015 are presented in Table 2. For MCC 007, MCC 009, and MCC 015, lowest radical spin density values of $0.000223,0.000230$, and 0.000214 were observed at the $16-\mathrm{OH}, 19-\mathrm{OH}$, and $3-\mathrm{OH}$, respectively. For each of these molecules, radicals obtained at these sites are the most stable. From Table 2, it is evident that these sites also possess the lowest BDE values for each of the molecules. Consequently, these are the preferred sites of free radical scavenge based on the HAT mechanism.

\section{Analysis of SET-PT mechanism}

The computed results of adiabatic ionization potential (AIP) and proton dissociation enthalpy (PDE) for MCC 007, MCC 009, and MCC 015 molecules at their various free radical scavenging sites in vacuum and water are presented in Table 2. The first step of the SET-PT mechanism for antioxidants is characterized by AIP. In the gas phase, the AIP results for the considered molecules in vacuum are appreciably lower than that of phenol $(572.776 \mathrm{~kJ} / \mathrm{mol}$ generated at the same level of theory) which is usually considered as a reference (Table 2). This indicates that these molecules are better electron donors compared to phenol in the gas phase. For MCC 007, MCC 009, and MCC 015 molecules, the sites with the best electron-donating ability are the 4$\mathrm{OH}, 4-\mathrm{OH}$, and $16-\mathrm{OH}$ positions with AIP values of $314.61 \mathrm{~kJ} / \mathrm{mol}, 381.14 \mathrm{~kJ} / \mathrm{mol}$, and $315.61 \mathrm{~kJ} / \mathrm{mol}$, respectively, in vacuum. However, in aqueous solution, the preferred site of electron donation is the $16-\mathrm{OH}$ position in each of the considered molecules. This position in each of these molecules has the lowest AIP value. The AIP value in aqueous solution is lower than the value in vacuum of each molecular site. Consequently, electron donation by these antioxidants is more favored in aqueous solution than in vacuum. Also, Table 2 indicates that the trend of AIP values of these curcumin derivatives is different from that of the computed BDE values. A possible explanation for this discrepancy is that AIP values are influenced by the structure of the entire molecule, such as the extended delocalization and conjugation of the $\pi$-electrons, whereas BDE of a given molecule is influenced by its local environment due to the substituents (Xue et al. 2014; Wang et al. 2015).

The PDE characterizes the second step of the SET-PT mechanism for antioxidants. MCC 007 has the lowest PDE values of $1275.23 \mathrm{~kJ} / \mathrm{mol}$ and $1612.42 \mathrm{~kJ} / \mathrm{mol}$ at the $16-\mathrm{OH}$ position in vacuum and aqueous solution, respectively. For MCC 009 and MCC 015 molecules, the values are $1104.08 \mathrm{~kJ} / \mathrm{mol}$ and $1475.71 \mathrm{~kJ} / \mathrm{mol}$ and $1100.03 \mathrm{~kJ} / \mathrm{mol}$ and $1474.80 \mathrm{~kJ} / \mathrm{mol}$ at the $19-\mathrm{OH}$ and $3-$ $\mathrm{OH}$ positions, respectively. These are the most favored sites for proton dissociation by SET-PT mechanism. The 
observed trend of PDE is analogous to those of BDE. This is not surprising since proton dissociation results in the generation of the antioxidant radical like bond dissociation. From the perspective of thermodynamics, the first step (in this case AIP) is the most important for reaction that involves multiple mechanisms such as the SET-PT.

\section{Analysis of SPLET mechanism}

The results of proton affinity (PA) and electron transfer enthalpy (ETE) for MCC 007, MCC 009, and MCC 015 in vacuum and water are presented in Table 2 . The first step of SPLET mechanism is characterized by the PA values, while ETE values characterize the second step. The PA results for MCC 007, MCC 009, and MCC 015 indicate that the most favored sites for deprotonation are the $16-\mathrm{OH}, 19-\mathrm{OH}$, and $3-\mathrm{OH}$ positions with $\mathrm{PA}$ values of $1367.07 \mathrm{~kJ} / \mathrm{mol}, 1362.35 \mathrm{~kJ} / \mathrm{mol}$, and 1358.25 $\mathrm{kJ} / \mathrm{mol}$, respectively, in vacuum. Deprotonation at these sites is more favorable than for phenol whose PA value is $1462.89 \mathrm{~kJ} / \mathrm{mol}$ (Table 2). In aqueous solution, a similar trend was observed for the molecules of MCC 007, MCC 009, and MCC 015 at the 16- OH, 19-OH, and $3-\mathrm{OH}$ positions with PA values of $335.80 \mathrm{~kJ} / \mathrm{mol}$, $339.24 \mathrm{~kJ} / \mathrm{mol}$, and $323.44 \mathrm{~kJ} / \mathrm{mol}$, respectively. The PA results in aqueous solution are lower than the values in vacuum for each considered molecular site. Thus, these curcumin antioxidant derivatives have a higher tendency to undergo deprotonation in aqueous solution than in vacuum. This could be attributed to the large solvation enthalpy of the proton.

The ETE value describes the ability of the antioxidant anion to transfer electrons to the free radical. The most favored sites for the second step of the SPLET mechanism in MCC 007, MCC 009, and MCC 015 are the 16$\mathrm{OH}, 19-\mathrm{OH}$, and $3-\mathrm{OH}$ positions in both vacuum and aqueous solution. These positions recorded the lowest
ETE values in each molecule (Table 2). However, deprotonation and electron transfer reactions of the SPLET mechanism occur more readily in aqueous solution than in the gas phase. A comparison of the generated results for ETE and AIP indicates that the ETE values are lower than those of AIP at a given scavenging site for each molecule in vacuum. This could be attributed to the fact that single electron transfer from the neutral form is less favored to that from the anionic form. This result is in agreement with previous research reported in the literature (Naik et al. 2011; Rimarcik et al. 2010 Xue et al. 2014).

\section{Evaluation of thermodynamically preferred mechanism}

The observed results of the Gibbs free energy change for scavenging $\mathrm{HOO}$. and $\mathrm{CH}_{3} \mathrm{OO}$. radicals via $\mathrm{HAT}$, SET$\mathrm{PT}$, and SPLET mechanisms by the considered curcumin antioxidants are presented in Tables 3 and 4, respectively. The thermodynamically preferred reaction is represented by the most negative reaction Gibbs free energy change $\left(\Delta_{r} G\right)$ result. This implies that in the assignment of the free radical scavenging potency of molecules, the $\Delta_{r} G$ result could very helpful.

In the gas phase, MCC 007 16-OH, MCC 009 19-OH, MCC 015 3-OH, and MCC 015 16-OH molecules possess good potency to scavenge $\mathrm{HOO}$. via the HAT and SPLET mechanism, because these processes are exergonic (Table 3). A similar trend was observed for the free radical scavenge of $\mathrm{CH}_{3} \mathrm{OO}$. (Table 4). For the SPLE $\mathrm{T}$ mechanism in vacuum, the exergonicity of $\Delta_{r} G_{P A}$ in the first step overwhelms the endergonicity of $\Delta_{r} G_{E T E}$ in the second step at these positions. This makes the entire SPLET mechanism thermodynamically feasible at these positions, because a thermodynamically unfeasible reaction could be driven by a thermodynamically feasible reaction that is coupled to it. The SET-PT mechanism in vacuum was thermodynamically unfeasible at all

Table 3 Gibbs free energy changes $\left(\Delta_{r} \mathrm{G}\right.$ in $\mathrm{kJ} / \mathrm{mol}$ ) of scavenging $\mathrm{HOO}$. radical by curcumin derivatives at the $\mathrm{B} 3 \mathrm{LYP}_{\mathrm{L}} \mathrm{6}-311 \mathrm{G} * / 6-31 \mathrm{G}^{*}$ level in vacuum and water

\begin{tabular}{|c|c|c|c|c|c|c|c|c|c|c|}
\hline \multirow[t]{3}{*}{ Comp No. } & \multirow{2}{*}{\multicolumn{2}{|c|}{$\frac{\mathrm{HAT}}{\Delta_{r} G_{B D E}}$}} & \multicolumn{4}{|l|}{ SET-PT } & \multicolumn{4}{|l|}{ SPLET } \\
\hline & & & \multicolumn{2}{|l|}{$\Delta_{r} G_{A I P}$} & \multicolumn{2}{|l|}{$\Delta_{r} G_{P D E}$} & \multicolumn{2}{|l|}{$\Delta_{r} G_{P A}$} & \multicolumn{2}{|l|}{$\Delta_{r} G_{E T E}$} \\
\hline & Gas & Water & Gas & Water & Gas & Water & Gas & Water & Gas & Water \\
\hline MCC 007 4-OH & 15.26 & 14.02 & 515.49 & $-74,398.17$ & -500.23 & $74,412.20$ & -256.59 & -63.66 & 271.85 & 77.68 \\
\hline MCC 007 16-OH & -12.23 & -21.47 & 446.15 & $-74,378.17$ & -458.38 & $74,356.69$ & -266.77 & -87.97 & 254.55 & 66.50 \\
\hline MCC 009 4-OH & 13.40 & 14.99 & 510.37 & $-74,382.92$ & -496.98 & $74,397.91$ & -255.22 & -62.98 & 268.62 & 77.97 \\
\hline MCC 009 16-OH & 38.915 & 27.49 & 521.87 & $-74,316.63$ & -482.96 & $74,344.12$ & -249.13 & -51.95 & 288.05 & 79.44 \\
\hline MCC 009 19-OH & -58.18 & -73.77 & 611.48 & $-74,305.49$ & -669.66 & $74,231.72$ & -271.40 & -73.09 & 213.22 & -0.69 \\
\hline MCC 015 3-OH & -56.26 & -64.79 & 617.34 & $-74,302.19$ & -673.60 & $74,237.39$ & -274.86 & -94.48 & 218.60 & 29.69 \\
\hline MCC 015 4-OH & 10.93 & 0.16 & 527.23 & $-74,273.80$ & -516.30 & $74,273.96$ & -275.15 & -87.29 & 286.08 & 87.45 \\
\hline MCC 015 16-OH & -13.36 & -18.06 & 446.92 & $-74,394.81$ & -460.27 & $74,376.75$ & -270.69 & -86.79 & 257.33 & 68.73 \\
\hline
\end{tabular}


Table 4 Gibbs free energy changes $\left(\Delta_{r} \mathrm{G}\right.$ in $\mathrm{kJ} / \mathrm{mol}$ ) of scavenging $\mathrm{CH}_{3} \mathrm{OO}$. radical by curcumin derivatives at the $\mathrm{B} 3 \mathrm{LYP} / 6-311 \mathrm{G}^{*} / 6$ $31 \mathrm{G}^{*}$ level in vacuum and water

\begin{tabular}{|c|c|c|c|c|c|c|c|c|c|c|}
\hline \multirow[t]{3}{*}{ Comp No. } & \multirow{2}{*}{\multicolumn{2}{|c|}{$\frac{\mathrm{HAT}}{\Delta_{r} G_{B D E}}$}} & \multicolumn{4}{|l|}{ SET-PT } & \multicolumn{4}{|l|}{ SPLET } \\
\hline & & & \multicolumn{2}{|l|}{$\Delta_{r} G_{A I P}$} & \multicolumn{2}{|l|}{$\Delta_{r} G_{P D E}$} & \multicolumn{2}{|l|}{$\Delta_{r} G_{P A}$} & \multicolumn{2}{|l|}{$\Delta_{r} G_{E T E}$} \\
\hline & Gas & Water & Gas & Water & Gas & Water & Gas & Water & Gas & Water \\
\hline MCC 007 4-OH & 18.50 & 16.65 & 477.47 & $-74,396.72$ & -458.97 & $74,413.37$ & -215.33 & -62.49 & 233.82 & 79.14 \\
\hline MCC 007 16-OH & -8.99 & -18.85 & 408.13 & $-74,376.71$ & -417.12 & $74,357.87$ & -225.52 & -86.8 & 216.52 & 67.95 \\
\hline MCC 009 4-OH & 16.63 & 17.62 & 472.35 & $-74,381.47$ & -455.72 & $74,399.09$ & -213.96 & -61.8 & 230.60 & 79.43 \\
\hline MCC 009 16-OH & 42.15 & 30.12 & 483.85 & $-74,315.17$ & -441.70 & $74,345.29$ & -207.87 & -50.78 & 250.02 & 80.9 \\
\hline MCC 009 19-OH & -54.94 & -71.15 & 573.46 & $-74,304.04$ & -628.40 & $74,232.89$ & -230.14 & -71.91 & 175.20 & 0.767 \\
\hline MCC 015 3-OH & -53.02 & -62.17 & 579.31 & $-74,300.73$ & -632.34 & $74,238.56$ & -233.60 & -93.31 & 180.58 & 31.14 \\
\hline MCC 015 4-OH & 14.17 & 2.788 & 489.21 & $-74,272.35$ & -475.04 & $74,275.14$ & -233.89 & -86.12 & 248.06 & 88.9 \\
\hline MCC 015 16-OH & -10.12 & -15.43 & 408.89 & $-74,393.36$ & -419.01 & $74,377.93$ & -229.43 & -85.62 & 219.31 & 70.18 \\
\hline
\end{tabular}

positions, because the first step of this pathway $\left(\Delta_{r} G_{A I P}\right)$ is endergonic and overwhelms the exergonicity of $\triangle_{r} G_{P D E}$. In addition, for a reaction that involves multiple mechanisms, the first step, in this case, $\Delta_{r} G_{A I P}$ is more important.

In aqueous solution, a similar trend was observed for the free radical scavenge of $\mathrm{HOO}$ and $\mathrm{CH}_{3} \mathrm{OO}$. radicals by HAT and SPLET mechanisms. In addition, the SET-PT mechanism was thermodynamically feasible at the MCC 007 16-OH, MCC 009 19-OH, MCC 015 3-OH, and MCC 015 16-OH positions in aqueous solution.
With respect to the chemical structures of the considered compounds, the $\Delta_{r} G$ is observed to be the most exergonic in situations where the $\mathrm{OH}$ group is attached to a nitrogen atom that also contains a methyl group. For instance, the molecule of MCC 009 is found to be the most exergonic in its reactions at the $19-\mathrm{OH}$ position. A similar trend is observed for MCC 015 at the 3-OH position. Consequently, this molecular structure confers improved antioxidant activity on these compounds. Comparison of the results in Tables 3 and 4 shows that the investigated curcumin antioxidants possess higher potential to scavenge $\mathrm{HOO}$. than $\mathrm{CH}_{3} \mathrm{OO}$.

(a)

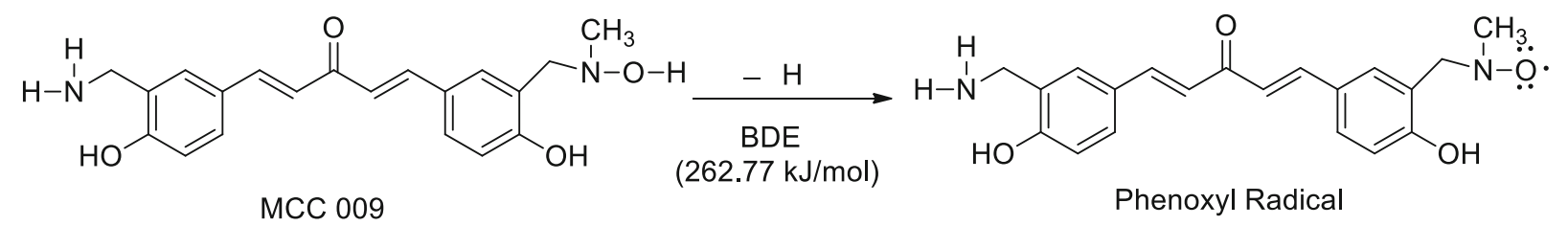

(b)

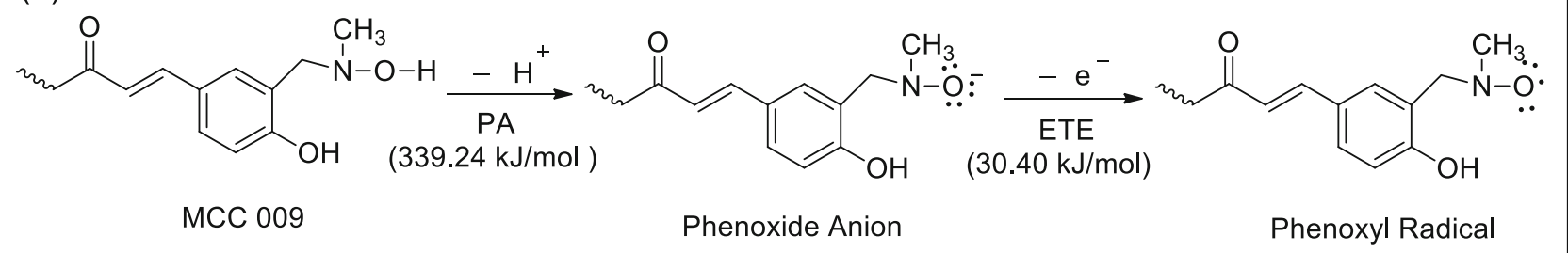

(c)

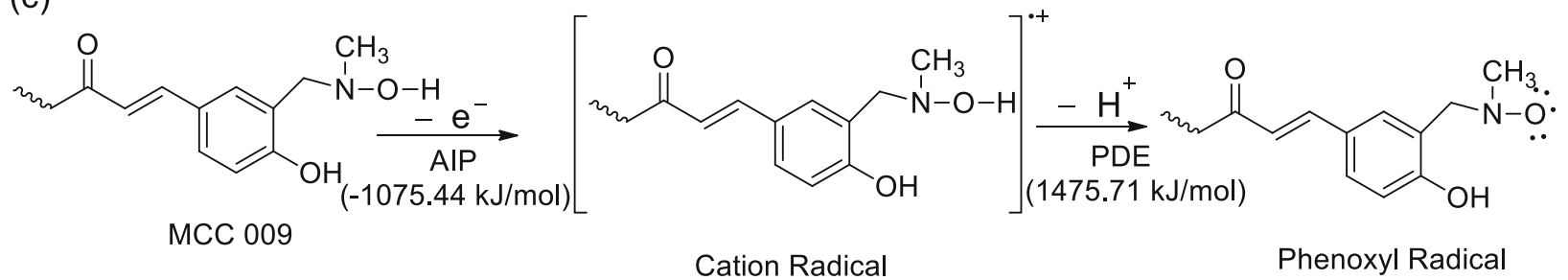

Scheme 1 a HAT mechanism of MCC 009 in vacuum. b SPLET mechanism of MCC 009 in water. c SET-PT mechanism of MCC 09 in water 
based on the exergonicity of their HAT, SPLET, and SET-PT mechanisms. The molecule MCC 009 at the 19$\mathrm{OH}$ position exhibited the highest potential to scavenge HOO and $\mathrm{CH}_{3} \mathrm{OO}$. by HAT, SPLET, and SET-PT mechanisms. Consequently, the mechanisms of free radical scavenge by this molecule by HAT, SPLET, and SET-PT mechanisms are presented in Scheme 1a-c, respectively.

\section{Analysis of frontier molecular orbitals}

Figure 3 gives the frontier orbital distribution and energy for MCC 007, MCC 009, and MCC 015 computed at the B3LYP/6-311G* level in the gas phase. The lowest unoccupied molecular orbital (LUMO) in the three molecules presents similar distributions and localized mainly on the isolated carbons that contains the ketone group. The highest occupied molecular orbital (HOMO) on the other hand is delocalized on the carbon atoms of the two phenyl rings, $\mathrm{A}$ and $\mathrm{B}$, and on the oxygen atoms that contain the hydroxyl group at the $4-\mathrm{OH}$ and $16-\mathrm{OH}$ sites of each molecule. These are the preferred sites of electron loss by these molecules. The 4-OH site which has a high density of HOMO distribution also has the lowest AIP value among the considered sites for each molecule (Table 2). Also, the $19 \mathrm{OH}$ site without HOMO distribution recorded the highest AIP result where it occurs in two of the considered molecules. Thus, the HOMO results are in good agreement with the computed AIP results. We have earlier indicated that AIP value describes the ability of the antioxidant to lose electrons to the free radical. These correspond to the 4-OH sites in each of the molecules MCC 07, MCC 09, and MCC 015. From the computed results of the HOMO energies for each of the three molecules, MCC 09 has the highest value of $-5.63 \mathrm{eV}$. This is closely followed by MCC 007 with a value of $-5.67 \mathrm{eV}$, while MCC 15 has the lowest value of $-5.76 \mathrm{eV}$. Recall that molecules with higher HOMO values have stronger electron-donating

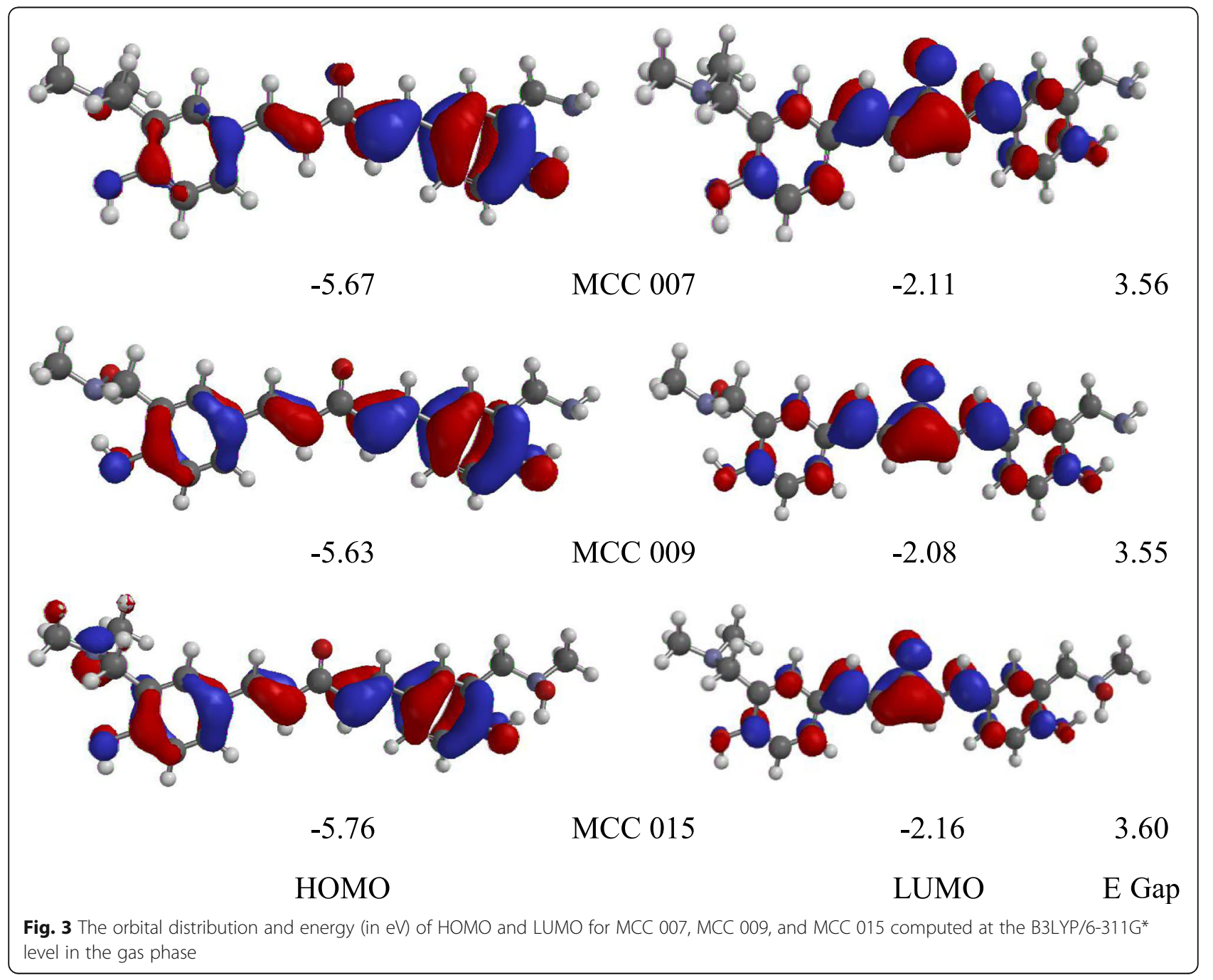


potentials (Özbakır Işın, 2016; Xue et al. 2014; Wang et al. 2015; Szeląg et al. 2011). Subsequently, MCC 09 has the strongest electron-donating ability, while MCC 15 has the weakest potential to donate electrons.

The results of HOMO-LUMO energy gap (E gap) for the considered curcumin antioxidants are also presented in Fig. 3. The reactivity of a molecule is reflected in its $\mathrm{E}$ Gap value. The lower E gap value for a given molecule is an indication of higher reactivity. Based on the E Gap results, MCC 009 has the lowest E gap value of $3.55 \mathrm{eV}$. This is in line with the sequence of predicted antioxidant activity of these compounds presented in Table 1 . In this Table, MCC 009 has the best antioxidant activity with a $p I C_{50}$ value of 6.260. MCC 09 was also predicted to have the highest potential to scavenge free radicals (Tables 3 and 4).

\section{Conclusion}

This research employed the technique of virtual screening to design a new set of curcumin antioxidants whose free radical scavenging potency was tested using the developed QSAR model. Three of these compounds, namely, MCCM 07, MCCM 09, and MCCM 15 showed better antioxidant activities compared to the template molecule. They were subsequently subjected to thermodynamic studies through the computation of their reaction enthalpies of free radical scavenge such as BDE, AIP, PDE, PA and ETE, and Gibbs free energy in the gas phase and aqueous solution. The three major mechanisms of free radical scavenge, namely, HAT, SET-PT, and SPLET were considered. The BDE revealed that MCCM 09 at the 19-OH position has the greatest ability to donate hydrogen atoms to the free radical in comparison to the other molecules, including phenol that was used as the reference molecule. The sequence of BDE value in these molecules was similar to that of PA, but different from that of AIP. Also, it was observed that single electron transfer from the neutral form is less favored to that from the anionic form as reflected in the computed ETE and AIP values.

In the molecules of MCCM 07 and MCCM 09, the thermodynamic feasibility for scavenging $\mathrm{HOO}$ and $\mathrm{CH}_{3} \mathrm{OO}$. radicals was observed at the $16-\mathrm{OH}$ and $19-\mathrm{OH}$ sites, respectively. For MCCM 15 molecule, 3-OH and $16-\mathrm{OH}$ sites were observed to be thermodynamically feasible. Also, these molecules showed greater scavenging potency for $\mathrm{HOO}$. than $\mathrm{CH}_{3} \mathrm{OO}$. by HAT, SET-PT, and SPLET mechanisms. In vacuum, these molecules could scavenge $\mathrm{HOO}$. and $\mathrm{CH}_{3} \mathrm{OO}$. radicals by HAT and SPLET mechanisms. The SET-PT mechanism was thermodynamically unfeasible in vacuum. In aqueous solution, MCCM 07, MCCM 09, and MCCM 15 could scavenge these peroxyl radicals by the three considered mechanisms. The exploration of the free radical scavenging potency of these curcumin derivatives in this research will arouse subsequent exploitation of these compounds in food chemistry and pharmacy.

\section{Abbreviations}

AIP: Adiabatic ionization potential; B3LYP: Becke's three-parameter Lee-YangParr hybrid functional; BDE: Homolytic bond dissociation enthalpy; DFT: Density functional theory; ETE: Electron transfer enthalpy; G: Gibbs free energy; H: Enthalpy; HAT: Hydrogen atom transfer; HOMO: Highest occupied molecular orbital; LUMO: Lowest unoccupied molecular orbital; PA: Proton affinity; PCM: Polarized continuum model; PDE: Proton dissociation enthalpy; QSAR: Quantitative structure activity relationship; SCRF: Self-consistent reaction field; SET-PT: Single electron transfer followed by proton transfer; SPLET: Sequential proton loss electron transfer; ZPE: Zero-point vibrational energy

\section{Acknowledgements}

The authors are grateful to the members of physical chemistry unit in Ahmadu Bello University Zaria, and ICT unit of Federal University Dutsinma for their assistance.

\section{Authors' contributions}

This research was designed by IOA, AU, and SEA. IOA optimized all the molecular structures. All authors participated in the calculation of the thermodynamic parameters. IOA wrote the manuscript under the supervision of $\mathrm{AU}$ and SEA. All authors read and approved the final manuscript.

\section{Funding}

This study was not funded by any institution or any other entity.

\section{Availability of data and materials}

The data generated or analyzed during this study are included in this published article, and the data used during the study are available from the article: Alisi IO, Uzairu A, Abechi SE, Idris SO (2018c) Evaluation of the antioxidant properties of curcumin derivatives by genetic function algorithm. J Adv Res 12 : 47-54. https://doi.org/10.1016/j.jare.2018.03.003.

Ethics approval and consent to participate Not applicable.

\section{Consent for publication \\ Not applicable.}

\section{Competing interests}

The authors declare that they have no competing interests.

\section{Author details}

'Department of Applied Chemistry, Federal University Dutsinma, PMB 5001 Dutsinma, Katsina State, Nigeria. ${ }^{2}$ Department of Chemistry, Ahmadu Bello University, Zaira, Kaduna State, Nigeria.

Received: 23 June 2020 Accepted: 2 August 2020

Published online: 20 August 2020

\section{References}

Aher RB, Wanare G, Kawathekar N, Kumar RR, Kaushik NK, Sahal D, Chauhan VS (2011) Dibenzylideneacetone analogues as novel plasmodium falciparum inhibitors. Bioorg Med Chem Lett. 21(10):3034-3036

Alisi IO, Uzairu A, Abechi SE (2019b) In silico design of hydrazone antioxidants and analysis of their free radical-scavenging mechanism by thermodynamic studies. Beni-Suef Univ J Basic Appl Sci. 8:11

Alisi IO, Uzairu A, Abechi SE (2020) Free radical scavenging mechanism of 1,3,4oxadiazole derivatives: thermodynamics of $\mathrm{O}-\mathrm{H}$ and $\mathrm{N}-\mathrm{H}$ bond cleavage. Heliyon. 6(3):e03683

Alisi IO, Uzairu A, Abechi SE, Idris SO (2018a) Quantitative structure activity relationship analysis of coumarins as free radical scavengers by genetic function algorithm. Phys Chem Res. 6(1):208-222

Alisi IO, Uzairu A, Abechi SE, Idris SO (2018b) Free radical scavenging activity evaluation of hydrazones by quantitative structure activity relationship. J Mex Chem Soc. 62(1):1-13 
Alisi IO, Uzairu A, Abechi SE, Idris SO (2018c) Evaluation of the antioxidant properties of curcumin derivatives by genetic function algorithm. J Adv Res. 12:47-54

Alisi IO, Uzairu A, Abechi SE, Idris SO (2019a) Development of predictive antioxidant models for 1,3,4-oxadiazoles by quantitative structure activity relationship. JOTCSA. 6(2):103-114

Amic A, Lučić B, Stepanić V, Marković Z, Marković S, Dimitrić Marković J, Amić D (2017) Free radical scavenging potency of quercetin catecholic colonic metabolites: thermodynamics of 2H+/2e- processes. Food Chem. 218:144-151

Asadollahi T, Dadfarnia S, Shabani AMH, Ghasemi JB, Sarkhosh M (2011) QSAR models for CXCR2 receptor antagonists based on the genetic algorithm for data preprocessing prior to application of the pls linear regression method and design of the new compounds using in silico virtual screening. Molecules. 16:1928-1955

Bartmess JE (1994) Thermodynamics of the electron and the proton. J Phys Chem. 98:6420-6424

Bayat A, Fattahi A (2017) The free radical scavenging activity of lespedezacoumestan toward ${ }^{-} \mathrm{OH}$ radical: a quantum chemical and computational kinetics study. J Phys Org Chem. 31(2):e3755

Bizarro MM, Cabral BJC, Santos RMB, Simoes JAM (1999) Substituent effects on the $\mathrm{O}-\mathrm{H}$ bond dissociation enthalpies in phenolic compounds: agreements and controversies. Pure Appl Chem. 71(7):1249-1256

Boulebd H, Mechler A, Hoa NT, Vo QV (2020) Thermodynamic and kinetic studies of the antiradical activity of 5-hydroxymethylfurfural: computational insights. New J Chem. 44:9863-9869

Chauhan IS, Rao GS, Shankar J, Chauhan LKS, Kapadia GJ, Singh N (2018) Chemoprevention of leishmaniasis: in - vitro antiparasitic activity of dibenzalacetone, a synthetic curcumin analog leads to apoptotic cell death in Leishmania donovani. Parasitol Int. 67(5):627-636

Din ZU, Fill TP, de Assis FF, Lazarin-Bidóia D, Kaplum V, Garcia FP, ... RodriguesFilho E (2014) Unsymmetrical 1,5-diaryl-3-oxo-1,4-pentadienyls and their evaluation as antiparasitic agents. Bioorg Med Chem. 22(3): 1121-1127.

Din ZU, Lazarin-Bidóia D, Kaplum V, Garcia FP, Nakamura CV, Rodrigues-Filho E (2016) The structure design of biotransformed unsymmetrical nitro-contained 1,5-diaryl-3-oxo-1,4-pentadienyls for the anti-parasitic activities. Arabian J Chem. 12(8):4006-4016

Fourches D, Ash J (2019) 4D- quantitative structure-activity relationship modeling: making a comeback. Expert Opin Drug Discovery. 14(12):12271235

Gabernet G, Gautschi D, Müller AT, Neuhaus CS, Armbrecht L, Dittrich PS, Hiss JA, Schneider G (2019) In silico design and optimization of selective membranolytic anticancer peptides. Sci. Rep. 9(11282):1-11

Galano A, Mazzone G, Alvarez-Diduk R, Marino T, Marino JR, Alvarez-Idaboy RN (2016) Food antioxidants: chemical insights at the molecular level. Annu Rev Food Sci Technol. 7(1):335-352

Gul A, Akhter Z, Perveen F, Kalsoom S, Ansari FL, Siddiq M (2019) Molecular docking and quantitative structure activity relationship (QSAR) studies of some newly synthesized poly (azomethine) esters. Int J Polym Sci. 2019:1-10

Hernandez DA, Rodriguez-Zavala JG, Tenorio FJ (2020) DFT study of antioxidant molecules from traditional Japanese and Chinese teas: comparing allylic and phenolic antiradical activity. Struct Chem. 31:359-369

Hwang S, Chung DS (2005) Calculation of the solvation free energy of the proton in methanol. Bull Kor Chem Soc. 26:589-593

Kondhare D, Deshmukh S, Lade H (2019) Curcumin analogues with aldose reductase inhibitory activity: synthesis, biological evaluation, and molecular docking. Processes. 7(7):417

Li Y, Toscano M, Mazzone G, Russo N (2018) Antioxidant properties and free radical scavenging mechanisms of cyclocurcumin. New J Chem. 42(15):269812705

Li Z, Wan H, Shi Y, Ouyang P (2004) Personal experience with four kinds of chemical structure drawing software: review on ChemDraw, ChemWindow, ISIS/Draw, and ChemSketch. J Chem Inf Comput Sci. 44(5):1886-1890

Marcou G, Flamme B, Beck G, Chagnes A, Mokshyna O, Horvath D, Varnek A (2019) In silico design, virtual screening and synthesis of novel electrolytic solvents. Mol Inf. 38:1-6

Mikulski D, Eder K, Molski M (2014) Quantum-chemical study on relationship between structure and antioxidant properties of hepatoprotective compounds occurring in cynara scolymus and silybum marianum. J Theor Comput Chem. 13(1):1-24

Mitra I, Saha A, Roy K (2011a) Chemometric QSAR modeling and in silico design of antioxidant no donor phenols. Sci Pharm. 79:31-58
Mitra I, Saha A, Roy K (2011b) Chemometric QSAR modeling and in silico design of antioxidant no donor phenols. Sci Pharm. 79:31-58

Naik N, Honnaiah VK, Swetha S (2011) 1,5-diphenylpenta-1,4 dien-3-ones: a novel class of free radical scavengers. Bulg. Chem. Commun. 43(3):460-464

Najafi M, Mood KH, Zahedi M, Klein E (2011) DFT/B3LYP study of the substituent effect on the reaction enthalpies of the individual steps of single electron transfer-proton transfer and sequential proton loss electron transfer mechanisms of chroman derivatives antioxidant action. Comput Theor Chem. 969:1-12

Nenadis N, Tsimidou MZ (2012) Contribution of DFT computed molecular descriptors in the study of radical scavenging activity trend of natural hydroxybenzaldehydes and corresponding acids. Food Res Int. 48:538-543

Özbakır Işın D (2016) Theoretical study on the investigation of antioxidant properties of some hydroxyanthraquinones. Mol Phys. 114(24):3578-3588

Perrier A, Eluard M, Petitjean M, Vanet A (2019) In silico design of new inhibitors against hemagglutinin of influenza. J Phys Chem. B 123:582-592

Pisoschi AM, Pop A (2015) The role of antioxidants in the chemistry of oxidative stress: a review. Eur J Med Chem. 97:55-74

Rimarcik J, Lukes V, Klein E, Ilcin M (2010) Study of the solvent effect on the enthalpies of homolytic and heterolytic $\mathrm{N}-\mathrm{H}$ bond cleavage in $\mathrm{p}$ phenylenediamine and tetracyano-p-phenylenediamine. J Mol Struct (THEOCHEM). 952:25-30

Ruscic B (2015) Active thermochemical tables: sequential bond dissociation enthalpies of methane, ethane, and methanol and the related thermochemistry. J Phys Chem A. 119(28):7810-7837

Shao Y, Molnar LF, Jung Y, Kussmann J, Ochsenfeld C, Brown ST et al (2006) Advances in methods and algorithms in modern quantum chemistry program package. Phys Chem Chem Phys. 8(27):3172-3191

Singh N, Chauhan IS (2018) MicroRNA expression profiling of dibenzalacetone (DBA) treated intracellular amastigotes of Leishmania donovani. Experimental Parasitology. 193:5-19

Sun F, Jin R (2013) Theoretical study on the radical scavenging activity of shikonin and its ester derivatives. Res J Appl Sci Eng Technol. 6(2):281-284

Sunil KRN, Badam R, Sattibabu R, Molli M, Sai Muthukumar V, Siva Sankara Sai S, Rao GN (2014) Synthesis, characterization and nonlinear optical properties of symmetrically substituted dibenzylideneacetone derivatives. Chem Phys Lett. 616-617:142-147

Szeląg M, Mikulski D, Molski M (2011) Quantum-chemical investigation of the structure and the antioxidant properties of a-lipoic acid and its metabolites. J Mol Model. 18(7):2907-2916

Tan BL, Norhaizan ME, Liew WPP, Rahman HS (2018) Antioxidant and oxidative stress: a mutual interplay in age-related diseases. Front Pharmacol. 9

Tissandier MD, Cowen KA, Feng WY, Gundlach E, Cohen MH, Earhart AD, Coe JV, Tuttle TRJ (1998) The proton's absolute aqueous enthalpy and Gibbs free energy of solvation from cluster-ion solvation data. J Phys Chem A. 102(40): 7787-7794

Vo QV, Nam PC, Bay MV, Thong NM, Cuong ND, Mechler A (2018) Density functional theory study of the role of benzylic hydrogen atoms in the antioxidant properties of lignans. Sci Rep. 8(1)

Wang G, Xue Y, An L, Zheng Y, Dou Y, Zhang L, Liu Y (2015) Theoretical study on the structural and antioxidant properties of some recently synthesised 2,4,5trimethoxy chalcones. Food Chem. 171:89-97

Williams CD, Carbone P, Siperstein FR (2019) In silico design and characterization of graphene oxide membranes with variable water content and flake oxygen content. ACS Nano. 13:2995-3004

Xue Y, Zheng Y, An L, Dou Y, Liu Y (2014) Density functional theory study of the structure-antioxidant activity of polyphenolic deoxybenzoins. Food Chem. 151:198-206

Yap CW (2011) PaDEL-descriptor: an open source software to calculate molecular descriptors and fingerprints. J Comput Chem. 32(7):1466-1474

Yehye W, Abdul Rahman N, Saad O, Ariffin A, Abd Hamid S, Alhadi A, Kadir FA, Yaeghoobi M, Matlob A (2016) Rational design and synthesis of new, high efficiency, multipotent schiff base-1,2,4-triazole antioxidants bearing butylated hydroxytoluene moieties. Molecules. 21(7):847

Yeung AWK, Tzvetkov NT, El-Tawil OS, Bungǎu SG, Abdel-Daim MM, Atanasov AG (2019) Antioxidants: scientific literature landscape analysis. Oxid Med Cell Longevity. 2019:1-11

Yousefinejad S, Mahboubifar M, Eskandari R (2019) Quantitative structureactivity relationship to predict the anti-malarial activity in a set of new 
imidazolopiperazines based on artificial neural networks. Malar J. 18(310): $1-17$

Yusuff OK, Abdul Raheem MAO, Mukadam AA, Sulaimon RO (2019) Kinetics and mechanism of the antioxidant activities of $\mathrm{C}$. olitorius and $\mathrm{V}$. amygdalina by spectrophotometric and DFT nethods. ACS Omega. 4(9):13671-13680

Zheng YZ, Deng G, Liang Q, Chen DF, Guo R, Lai RC (2017) Antioxidant activity of quercetin and its glucosides from propolis: a theoretical study. Sci Rep. 7: 7543

Zhou H, Li X, Shang Y, Chen K (2019) Radical scavenging activity of Puerarin: a theoretical study. Antioxidants. 8:590

\section{Publisher's Note}

Springer Nature remains neutral with regard to jurisdictional claims in published maps and institutional affiliations.

\section{Submit your manuscript to a SpringerOpen ${ }^{\mathcal{O}}$ journal and benefit from:}

- Convenient online submission

- Rigorous peer review

- Open access: articles freely available online

High visibility within the field

- Retaining the copyright to your article

Submit your next manuscript at $\boldsymbol{\nabla}$ springeropen.com 